\title{
How effective is information on soil-landscape units for determining spatio-temporal variability of near-surface soil moisture?
}

\author{
Paolo Nasta, ${ }^{1}$ Benedetto Sica, ${ }^{2}$ Caterina Mazzitelli, ${ }^{2}$ Paola Di Fiore, ${ }^{1}$ Ugo Lazzaro, ${ }^{2}$ Mario Palladino, ${ }^{1}$ \\ Nunzio Romano ${ }^{1,2}$
}

${ }^{1}$ Department of Agricultural Sciences, AFBE Division, University of Napoli Federico II, Portici (NA);

${ }^{2}$ The Interdepartmental Center for Environmental Research, University of Napoli Federico II, Napoli, Italy

\begin{abstract}
In the last decades, a growing interest in fostering advanced interdisciplinary studies is leading to the establishment of observatories in pilot catchments for long-term monitoring of hydrological variables and fluxes. Nevertheless prior to sensor network installation, this investment necessitates preliminary surveys on key-variables such as near-surface soil moisture in order to prevent risks of erronously distributing sensors by missing sufficient spatial information for understanding hydrological processes within the landatmosphere interactions. The availability of maps describing areas with similar morphological, topographical, soil, and vegetation characteristics enable preliminary surveys to be organized for capturing spatio-temporal variability of soil moisture as best as possible. The soil-landscape classification can be considered as an interesting approach for grouping mapping units with similar hydrological behavior. Therefore, we assume the soil-landscape units as hydrotopes or hydrological similar units. Six transects were established along two hillsides of the Upper Alento River catchment (southern Italy) which is a proper candidate to become a Critical Zone Observatory. In this paper we use a soil-landscape map to infer spatial and temporal dynamics of soil moisture measured along these transects, whereas quantitative analyses were obtained by using multivariate techniques. The effectiveness of available
\end{abstract}

Correspondence: Paolo Nasta, Department of Agricultural Sciences, AFBE Division, University of Napoli Federico II, via Università 100, 80055 Portici (NA), Italy.

E-mail: paolo.nasta@unina.it

Key words: Hydrotope; topography; temporal stability; spatial variability; time domain reflectometry; partial least squares regression.

Acknowledgements: the study reported in this paper was supported in part by the MiUR-PRIN Project Innovative methods for water resources management under hydro-climatic uncertainty scenarios (grant 2010JHF437).

Received for publication: 11 December 2017.

Accepted for publication: 6 May 2018.

CCopyright P. Nasta et al., 2018

Licensee PAGEPress, Italy

Journal of Agricultural Engineering 2018; XLIX:822

doi:10.4081/jae.2018.822

This article is distributed under the terms of the Creative Commons Attribution Noncommercial License (by-nc 4.0) which permits any noncommercial use, distribution, and reproduction in any medium, provided the original author(s) and source are credited. information on soil-landscape mapping units is evaluated with respect to different observed patterns of soil moisture: wetter- and drier-than average observation points belong to agricultural and forested hillslopes, respectively. Soil texture and topographical controlling factors, especially clay content and slope gradient, are found to explain approximately $70 \%$ of the observed spatial variations in soil moisture along the forested hillslopes. The spatial structure explained by the environmental controlling factors decreases to $45 \%$ in the cases of the agricultural hillslopes mainly due to perturbations induced by grazing and tillage practices.

\section{Introduction}

Agro-forestry ecosystems around the Mediterranean Belt are facing up pressures induced by socio-economic factors that, among other things, have caused agricultural abandonment and relatively rapid land-use changes especially in the hilly and mountaneous zones of southern Europe (Ruiz-Sinoga et al., 2011; Nasta et al., 2017). These factors combined with projected climate changes may have important environmental implications and definitely affect the ecosystem goods and services provided by rural areas, particularly that subset more related to catchment-scale management of water resources. For example, in the presence of reservoirs created by multi-purpose dams, it is strategic to set up reliable water yield predictions accounting for the afforestation and land-use changes caused by farmland abandonment. The attention in the next decades will be therefore directed toward a better description of the mechanisms that govern the hydrological processes in the soil-vegetation-atmosphere system to tackle the aforementioned ecosystem vulnerabilities efficiently across the catchments in the Mediterranean Belt. An ideal approach would be based on scheduling dense sampling measurements of state variables and fluxes in critical zone observatories over different climatic regions (Vereecken et al., 2015). Yet, despite recent technological advancement, huge efforts and costs limit the applicability of long-term monitoring infrastructures especially when increasing the spatial scale of interest. Near-surface soil moisture is a key variable to synthesize the hydrological processes occurring in the vadose zone since it controls the exchange of water fluxes at land surface (Vereecken et al., 2008). Near-surface soil moisture can be monitored by using different measurement techniques (Vereecken et al., 2008), but recent progress in sensing techniques is providing new opportunities to map near-surface soil moisture patterns at unprecedented spatial and temporal resolutions (Romano, 2014). However, it is extremely important to maximize the information content gathered from observed soil moisture dynamics while minimizing logistic constraints (Chaney et al., 2015). Knowledge of soil moisture spatio-temporal variations retrieved from preliminary measurement campaigns is a valuable basic 
information to design optimal schemes for installing new-generation of ground-based sensor networks.

Preliminary surveys are usually carried out by using costeffective portable measurement devices so as to cover most of mapping units and gain knowledge on soil moisture patterns. Time domain reflectometry (TDR) is a very popular technique to indirectly measure soil moisture and offers a relatively high degree of precision if calibrated properly (Robinson et al., 2008; Romano, 2014; Susha Lekshmi et al., 2018).

The study presented in this paper tackles the problem of assessing the spatio-temporal dynamics of hillslope-scale soil moisture patterns while benefitting from the prior knowledge of a soil-landscape map (Santini et al., 1999). The study area is the Upper Alento River Catchment (UARC) located in southern Italy where field campaigns and various activities are under way since more than a decade to make it a critical zone observatory (Romano et al., 2018). Prior available information is represented by the soillandscape units map that describes and synthesizes topographic, geomorphological, soil, and land-use features (Vincent et al., 2018). Some authors attempted to combine information on topography, soil type, and land-use to define landscape units with similar hydrological behavior by introducing the so-called hydrotopes or hydrological similar units (Page et al., 2007; Friesen et al., 2008). This way one can test spatial organization of soil moisture explained by surrogate (or auxiliary) variables (defined also as proxy data) within each hydrotope (Beaudette et al., 2013; Liang et al., 2017).

The two main research questions arising before planning sampling schemes of new-generation sensors are: i) How do we optimally exploit a priori information from available soil-landscape units map to capture spatio-temporal dynamics of soil moisture? ii) What is the degree of soil moisture spatial variation explained by proxy information given by soil and topographical attributes?

In the following sections we will discuss these research questions and provide some guidelines on how to address the abovementioned issues.

\section{Materials and methods}

\section{Environmental setting}

The UARC is located in the Salerno Province (Campania Region, Italy) and has a drainage area of approximately $102 \mathrm{~km}^{2}$. The reader interested in gaining more details on this study area is directed to the paper by Nasta et al. (2017) and Romano et al. (2018). Topographical attributes such as slope and aspect angles, profile and tangential curvatures, and contributing area were retrieved from a $5 \mathrm{~m}$ grid size digital elevation model. Significant changes in land-use were observed since the post War World II period up to nowadays mostly due to socio-economic controlling factors (Nasta et al., 2017). In 1958 we report land-use situation with $75 \%$ area covered by permanent crops, arable and pasture lands, and $20 \%$ covered by forest. Rural abandonment has led to forest re-expansion (43\% in 1998 and 69\% in 2015) and significant reduction of pasturland and cropland.

The soil-landscape units represent homogeneous zones within the UARC characterized by similar environmental features such as soil, topography, morphology and land use (Park and van de Giesen, 2004). Soil types along the hillslopes were analyzed by visual interpretation of aerial photogrammetry and soil survey techniques based on excavation of 37 pedological pits throughout the UARC (Nasta et al., 2017). Soil was then classified according to Soil Taxonomy (USDA, 1996).

\section{Field measurements}

Most of the field surveys were carried out along a few hillsides of the eastern portion of UARC (about $37 \mathrm{~km}^{2}$ ) (see Figure 1 of Nasta et al., 2009). The dominant soil-landscape units and subunits are shown in Figure 1 and their brief description is presented as follows:

- $\quad V A G$ : clay flysch on calcareous debris generated by the weathering process of the overlying calcareous substratum. Soil

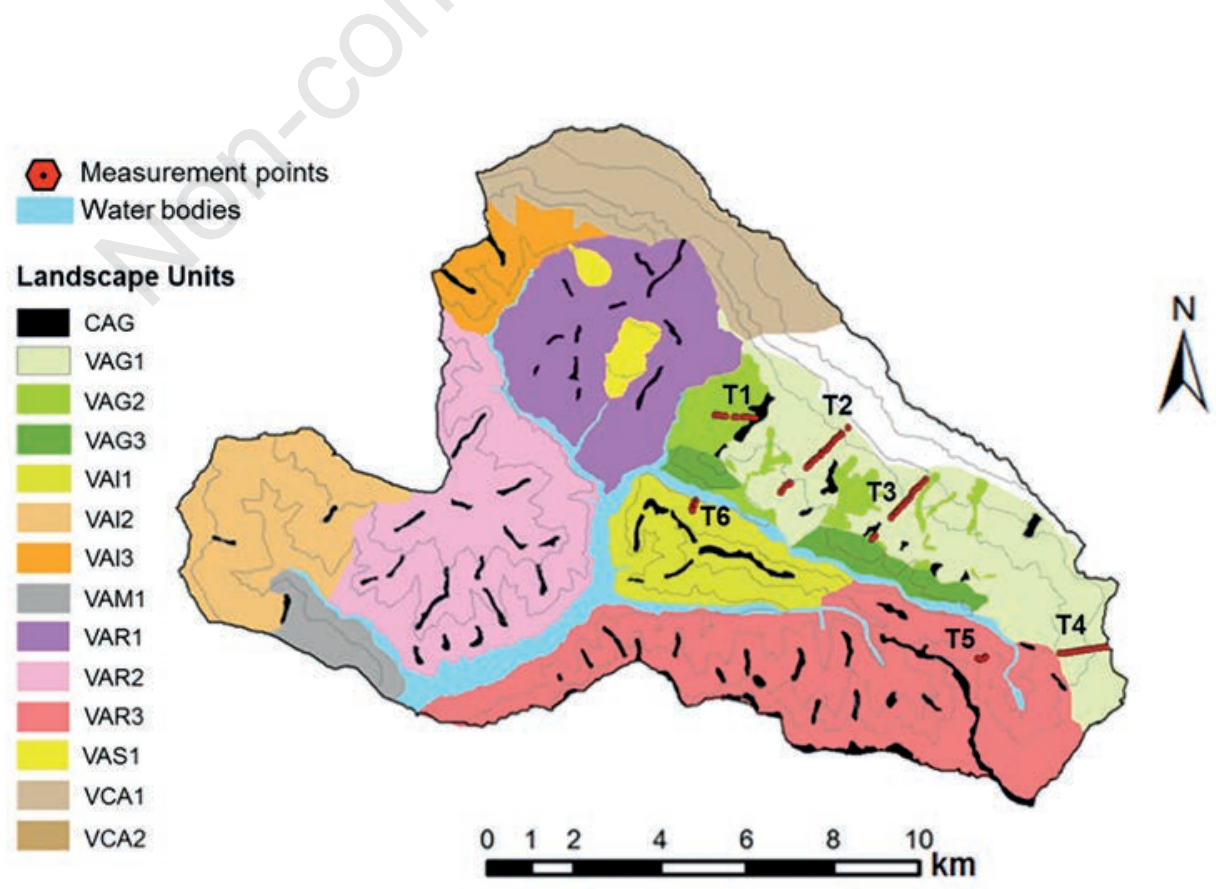

Figure 1. Soil-Landscape units map of Upper Alento River catchment (UARC) and location of the 82 measurements points distributed along six hillslope-transects (T1, T2, T3, T4, T5, T6). 
types are Typic Ustorthent, Typic Haplustept, Chromic Calciustert Land use is arable and pasture land with presence of orchards and arboreous plantations incentivated by European Union funds. We distinguish three sub-units: i) $V A G 1$ : stable (slope between $10 \%$ and $30 \%$ ) hillslopes covered by arable land and olive orchards; ii) VAG2: unstable hillslopes (slope between 20\% and 40\%), land use is arable land and olive orchards; iii) VAG3: stable (slope between $4 \%$ and 10\%) hillslopes with deposits of clay material in the valley floors, land use is riparian vegetation by the river channel and forest.

- VAR: very steep (slope between $30 \%$ and $60 \%$ ) hillslopes on arenaceous-pelitic flysch. Elevation between 200 and $650 \mathrm{~m}$ a.s.l. Soil types are Typic Ustorthent and Andic Haplustept over pyroclastic parent material. Land use is Mediterranean macchia, shrubs and oak woods. We report only one sub-unit: i) VAR3 is set on the north-face hillslope with dense forest of oak and chestnut trees.

- VAI: moderately steep (slope between 20\% and 40\%) hillslopes on arenaceous-pelitic flysch. Elevation between 150 and $500 \mathrm{~m}$ a.s.l. Soil type is Typic Haplustept and vegetation cover is dominated by chestnut trees. We report only one subunit: i) VAII is set on the north-face hillslope with dense forest of oak and chestnut trees.

- $\quad C A G$ : Patchy sharp ridges subjected to intense soil erosion and high risk of landslides.

Six hillslope transects, with a total of 105 measurement points, were established in the study catchment with almost all sampling locations spaced $50 \mathrm{~m}$ apart (Nasta et al., 2009). Four longer transects (T1, T2, T3 and T4) were established across the south-west facing hillslopes crossing the VAG soil-landscape unit, especially VAG1 sub-unit that is the dominant one over the other two VAG sub-units (Figure 1). Two additional, but shorter transects (T5 and T6) were selected across the VAR3 and VAI1 soil-landscape units and oriented in the SW-NE direction along the main slope. In this study, we present the measurements of near-surface soil moisture carried out in the same transects. However, the observation points were reduced from 105 to 82 due to logistic constraints such as imperviousness and denials to enter in a few privatelands during soil tillage operations. Table 1 in Nasta et al. (2009) lists the summary statistics of the 105 soil physical properties such as USDA textural classes (\%sand, \%silt, \%clay), soil bulk density $(\rho \mathrm{b})$, and soil organic matter.

Near-surface soil moisture values were measured by using a portable TDR device, specifically designed at the Laboratory of
Soil Hydrology of University of Napoli Federico II, over ten field campaigns, from October, $7^{\text {th }} 2004$ to January, $11^{\text {th }} 2005$. During the first, second and fourth sampling days, the very dry clayey soil surface was very hard for probe insertion, and this caused damages for several homemade probes. In presence of soil surface cracks when local drier conditions occurred, some more significant measurement errors can be expected due to air gaps around the metal rods of TDR probes. Later on, the sampling days were mostly established after significant rainfall events.

\section{Statistical analysis}

Datasets of soil moisture values are summarized through basic indices of descriptive statistics such as mean, median, standard deviation, coefficient of variation, minimum and maximum. Given the soil moisture values $\theta_{i j}$ at position $i$ and measurement time $j$, we define $\overline{\theta_{j}}$ as the spatial average of soil moisture observations at time $j$ and site $i$. We define as well $\mu_{j}$ as the mean of the population of soil moisture values at time $j$. Since the number of sampling locations is small $(\mathrm{I}=82)$ and population standard deviation at time $j$ is a-priori unknown, we use the Student's $t$-distribution for assessing $90 \%(\mathrm{a}=0.05)$ confidence intervals around $\overline{\theta_{j}}$ :

$$
\mu_{j}=\bar{\theta}_{j} \pm t_{D F, \alpha} \frac{S_{j}}{\sqrt{I}}
$$

where $S_{j}$ is sample standard deviation at time $j$ and DF are I-1 degrees of freedom. We identify the confidence interval, $I C_{j}$ at time $j$ :

$$
I C_{j}=t_{D F, \alpha} \frac{S_{j}}{\sqrt{I}}
$$

If both terms of Eq. (2) are divided by $\overline{\theta_{j}}$ and multiplied by 100 , we obtain the percentage confidence error, $\mathrm{E}_{\mathrm{j}} \%$ defined as:

$$
E_{j} \%=t_{D F, \alpha} C V_{j} \frac{1}{\sqrt{I}}
$$

where $\mathrm{CV}_{\mathrm{j}}$ is the coefficient of variation at time $j$ (Wang et al., 2008).

The temporal structure of soil moisture variability is assessed

\begin{tabular}{|c|c|c|c|c|c|}
\hline Sampling dates & Spatial-average & Standard deviation & Coefficient of variation & Skewness & Normality test \\
\hline 7-ott-04 & 0.169 & 0.100 & 59.4 & 0.21 & $\mathrm{~N}^{*}$ \\
\hline 20-ott-04 & 0.304 & 0.100 & 33.0 & -0.26 & $\mathrm{~N}$ \\
\hline 29-ott-04 & 0.132 & 0.057 & 43.3 & 0.82 & $\mathrm{NN}^{* *}$ \\
\hline 5-nov-04 & 0.105 & 0.044 & 42.4 & 1.00 & NN \\
\hline 11-nov-04 & 0.355 & 0.074 & 20.8 & 0.15 & $\mathrm{~N}$ \\
\hline 16-nov-04 & 0.330 & 0.072 & 21.9 & -0.05 & $\mathrm{~N}$ \\
\hline 30-nov-04 & 0.352 & 0.087 & 24.6 & -0.30 & $\mathrm{~N}$ \\
\hline 7-dic-04 & 0.345 & 0.078 & 22.7 & -0.18 & $\mathrm{~N}$ \\
\hline 19-dic-04 & 0.366 & 0.084 & 23.1 & -0.51 & $\mathrm{~N}$ \\
\hline 11-gen-05 & 0.319 & 0.079 & 24.8 & 0.08 & $\mathrm{~N}$ \\
\hline
\end{tabular}

Table 1. Main statistical properties of the soil moisture data collected during the ten sampling campaigns in the study area. Normality test is the Lilliefors test at the $5 \%$ significance level.

*Normal; **not normal. 
through the methodology originally proposed by Vachaud et al. (1985) and later applied by many other authors (Comegna and Basile, 1994; Martínez-Fernández and Ceballos, 2003; Brocca et al., 2009; Coppola et al., 2011; Brocca et al., 2012; Vanderlinden et al., 2012). While defining $\delta_{i j}$ as the spatial relative difference between $\theta_{i j}$ and $\overline{\theta_{j}}$, the temporal variability of soil moisture spatial patterns can be assessed through the analysis of the time average $\bar{\delta}_{i}$, computed as follows:

$$
\bar{\delta}_{i}=\frac{1}{J} \sum_{j=1}^{J} \delta_{i j}
$$

with

$$
\delta_{i j}=\frac{\theta_{i j}-\bar{\theta}_{j}}{\bar{\theta}_{j}}
$$

where $J$ is the total number of sampling days ( $J=10$ in our case study). Negative and positive values of $\overline{\delta_{i}}$ indicate underestimates and overestimates of $\overline{\theta_{j}}$, respectively.

Low values of standard deviation of $\delta_{i}$, namely $\sigma\left(\delta_{i}\right)$, diagnose time-stable locations (Vachaud et al., 1985). The index of time stability (ITS) is defined as follows:

$$
\operatorname{ITS}_{i}=\left[\bar{\delta}_{i}^{2}+\sigma^{2}\left(\delta_{i}\right)\right]^{1 / 2}
$$

The measurement location with minimum ITS index is identified as the representative point of areal mean soil moisture for the study area (Jacobs et al., 2004; Zhao et al., 2010). Moreover the Spearman non-parametric test indicates temporal persistence of the ranks among the different positions. By defining $R_{i, j}$ and $R_{i, j}$ ' as the rank soil water content at site $i$ at two different times $(j$ and $j$ '), the Spearman rank correlation coefficient $\left(r_{S}\right)$ is calculated as:

$$
r_{s}=1-\frac{6 \sum_{i=1}^{I}\left(R_{i, j}-R_{i, j^{\prime}}\right)}{I\left(I^{2}-1\right)}
$$

where $I$ is the total number of spatial positions ( $I=82$ in our case study). A value of $r_{S}=1$ ideally indicates perfect temporal stability of the analyzed process between times $j$ and $j$ '.

Partial least-squares regression (PLSR) was used to define the explained variance of soil moisture patterns by exploiting cross-correlated soil-terrain predictor variables (Huang et al., 2016). Soil proxy data are the percentages of sand, silt, and clay contents, soil organic matter and bulk density, whereas topographical auxiliary variables considered in this study are aspect, slope gradient, tangential curvature, profile curvature, and contributing area (Martínez-Fernández and Ceballos, 2003; Romano and Chirico, 2004). This technique generates new predictor variables (components) as linear combinations of the original predictors. PLSR finds combinations of the predictors that have a large covariance with the soil moisture patterns. The predictive ability of the PLSR will be expressed in terms of the coefficient of determination $\left(\mathrm{R}^{2}\right)$ and root mean squared error (RMSE), which evaluate the scatter of the data points around the fitted regression curve and the bias between observed and modeled soil moisture values, respectively.

\section{Results}

\section{Analysis of spatio-temporal variability of soil moisture data set}

Figure 2 shows the ten (white squares) soil moisture spatialmedian values with their $25^{\text {th }}-75^{\text {th }}$ percentiles (black lines) with rainfall data (cyan bars), whereas Table 1 reports summary metrics pertaining to soil moisture values measured at each sampling day. We observe a dry stage with spatial-median soil moisture values below $0.3 \mathrm{~cm}^{3} \mathrm{~cm}^{-3}$ and relatively high coefficient of variations $(\mathrm{CV} \mathrm{s})$ in the first four sampling measurements despite the occurrence of two close rainfall events higher than $20 \mathrm{~mm} / \mathrm{d}$. For soil moisture data gathered during the $3^{\text {rd }}$ and $4^{\text {th }}$ measurement campaigns, the null hypothesis of normal distributions should be rejected according to Lilliefors test at 5\% significance level. In contrast, observed positively skewed distributions diagnose presence of wetter-than-average observation points that might be dominated by non-local controls.

A subsequent wet stage is identified from November 2004 up to January 2005 with spatial-median values steadily above $0.3 \mathrm{~cm}^{3}$ $\mathrm{cm}^{-3} . C V_{\mathrm{s}}$ halve and measurements are all normally distributed. Skewness decreases and becomes negative when spatial-average soil moisture increases, as also observed by Famiglietti et al. (2008). In this case, drier-than-average observation points might be controlled by local factors such as soil cracks that favor preferential flow (Grayson et al., 1997). Observed soil moisture distributions are approximately symmetric (skewness between -0.20 and +0.20 ) when spatial-average soil moisture ranges between 0.32 and $0.36 \mathrm{~cm}^{3} \mathrm{~cm}^{-3}$.

In the following we shall analyze whether temporal stability determined by the Spearman's rank correlation metric persists during the dry and wet stages. Table 2 shows all combinations of Spearman's correlation coefficients. Red and blue values correspond to combinations within dry stage and within wet stage whereas black values express those combinations between dry and wet stages. The nonparametric Spearman's test demonstrates that in general there is no perfect time stability at any time. We observe $r_{s}$-values generally either higher (Brocca et al., 2009) or lower (Martínez-Fernandez and Ceballos, 2003) than those reported in similar studies under Mediterranean climate. Indeed vegetation dynamics and land use change induced by grazing, tillage practices and harvesting in the VAG unit might perturb the strength of tem-

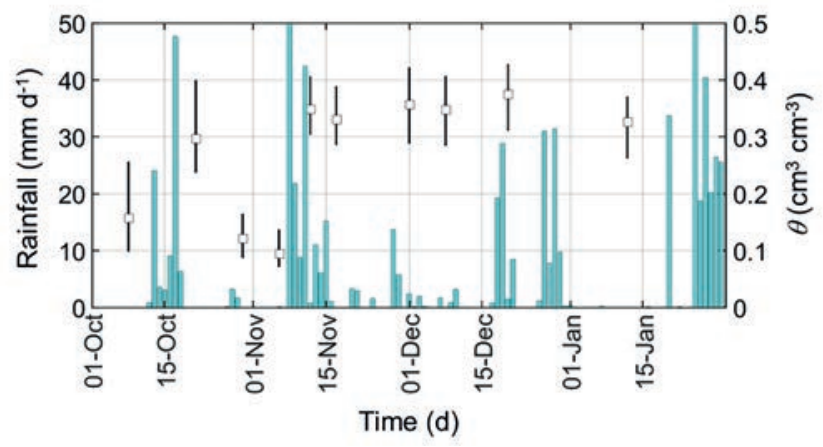

Figure 2. Daily rainfall data (cyan bars) spanning from October 2004 to January 2005 with median soil moisture values (white squares) taken during the ten measurement campaigns. Vertical gray bars indicate the range between $25^{\text {th }}$ and $75^{\text {th }}$ percentiles. 
poral stability (Gómez-Plaza et al., 2000; Schneider et al., 2008). Yet, sampling measurements during the wet stage show relatively high correlation ( $r_{s}$ above 0.65 ), implying that hydrological processes influencing soil moisture patterns might be temporally stable. On the contrary, time stability of soil moisture patterns within dry stage tend to decrease. Nevertheless it is as well interesting to observe that time stability increases under wetter conditions.

\section{Controlling factors on temporal stability of soil moisture}

Figure 3 shows the time-average plot of the relative soil moisture differences $\left(\overline{\delta_{i}}\right.$, are solid circles and $\sigma\left(\delta_{i}\right)$ are gray bars) and associated ITS (green line). Moreover the $\overline{\delta_{i}}$-values are associated to the corresponding soil-landcsape units (VAG1, VAG2, VAG3, VAR3 and VAI1 and CAG) as presented in a similar fashion by

Wang et al. (2015). The $\overline{\delta_{i}}$-values, referred to an area of about 37 $\mathrm{km}^{2}$, span from $-46 \%$ to $+50 \%$ which are values surprisingly larger than those obtained in previous studies applied in more extended catchments (Martínez-Fernández and Ceballos, 2003; Brocca et al., 2010; Brocca et al., 2012; Wei et al., 2017). The time-average plot of the relative soil moisture differences shows locations that systematically overestimate $\left(\overline{\delta_{i}}>0\right)$ or underestimate

$\left(\overline{\delta_{i}}<0\right)$ the spatial-average soil moisture (Coppola et al., 2011). It is evident that the wetter-than-average zones belong to the dominant soil-landscape unit, VAG (as visually indicated by the clustering of bluish circles on the right part of the plot) and soil moisture patterns are characterized by large standard deviations (from $9 \%$ to $58 \%$ ). On the other hand the drier-than-average zones in the remaining soil-landscape units are characterized by values of $\sigma\left(\delta_{i}\right)$ ranging from 7\% up to 31\% (Hu et al., 2010; Wei et al., 2017). Nonetheless, temporal stability is assessed through the ITS-index which is maximum for wettest and driest conditions and minimizes toward the centre of the plot corresponding to the ideal point $\overline{\delta_{i}}=0$. There are two local minima with ITS $=8.8$ and ITS $=10.1$ at locations $38\left(\overline{\delta_{i}}=-4.6 \%\right)$ and $46\left(\overline{\delta_{i}}=+2.3 \%\right)$, respectively, indicating the highest degree of temporal stability. Both locations belong to the VAG unit and can be both considered as representive points of the study area. Nevertheless, additional analysis of temporal stability should be based on the replacement of spatial mean soil moisture with field capacity to distinguish between fast-flow and capillary-flow locations as recently recommended by Lai et al.
(2018). Below, we examine the role exerted by soil (clay, silt, sand contents, soil organic matter, and soil bulk density) and topographical (aspect, slope, planar and tangential curvature, contributing area) characteristics in determinining the spatial organization of soil moisture. However, we caution the reader that the most probable influence of vegetation is neglected in this study for lack of direct measurements. Table 3 lists the Pearson's correlation coefficients between $\overline{\delta_{i}}$ and the environmental controls. Only five correlation coefficients are significant at the $p$-level $<0.05$. Soil moisture patterns are more sensitive to clay content (positive correlation) and slope (negative correlation). In other words, wetter-thanaverage zones (corresponding to VAG units) are determined by clayey soils on hillslopes with moderate slopes. The non-dominant soil-landscape units are characterized by arenaceous soils (sandy texture), steep slopes and forest cover. In order to corroborate these observations, Figure 4 shows an illustrative example on the relationship between clay content and $\delta$-values. Clay content is expressed as relative difference $\left(\mathrm{RD}_{\text {clay }}\right)$ between clay at location $i$ and clay content at location 38, considered as benchmark point with lowest ITS-value (white square that is almost at the centre of the plot where both $\mathrm{RD}_{\text {clay }}$ and $\delta$ are zero). Figure 4 presents also a regression line expressing the relationship between clay and $\delta$

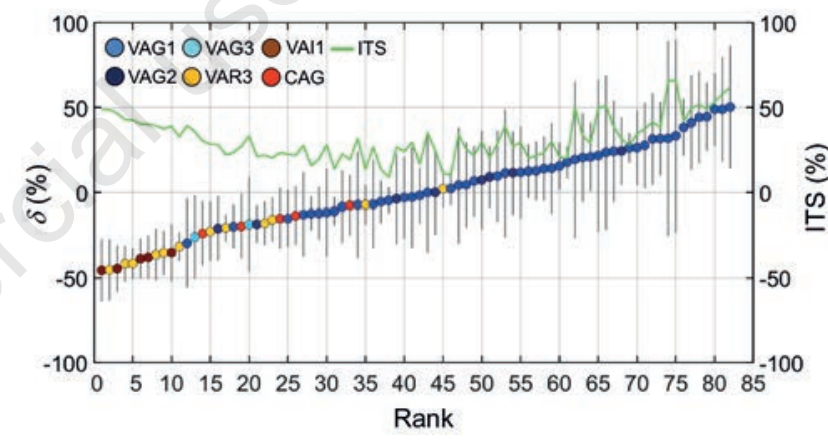

Figure 3. Ranked time average relative difference, $\overline{\delta_{i}}$ (solid circles) and index of time stability, ITS (green line) for the 82 sampling points. Solid circles are colored according to soil-landscape units. Error bars indicate \pm 1 standard deviation of relative difference at each location $\mathrm{i}, \delta_{i}$.

Table 2. Matrix of nonparametric Spearman's correlation coefficients among soil moisture data collected during the ten sampling campaigns in the study area.

\begin{tabular}{|c|c|c|c|c|c|c|c|c|c|c|}
\hline & 7-ott-04 & 20-ott-04 & 29-ott-04 & 5-nov-04 & 11-nov-04 & 16-nov-04 & 30-nov-04 & 7-dic-04 & 19-dic-04 & 11-gen-05 \\
\hline 7-ott-04 & $1^{* * *}$ & & & & & & & & & \\
\hline 20-ott-04 & $0.305^{*}$ & $1^{* * *}$ & & & & & & & & \\
\hline 29-ott-04 & $0.294^{*}$ & $0.777^{*}$ & $1^{* * *}$ & & & & & & & \\
\hline 5-nov-04 & $0.210^{*}$ & $0.718^{*}$ & $0.809^{*}$ & $1^{* * *}$ & & & & & & \\
\hline 11-nov-04 & $0.337^{* * *}$ & $0.818^{* * *}$ & $0.737^{* * *}$ & $0.733^{* * *}$ & $1^{* * *}$ & & & & & \\
\hline 16-nov-04 & $0.303^{* * *}$ & $0.784^{* * *}$ & $0.753^{* * *}$ & $0.710^{* * *}$ & $0.885^{* *}$ & $1^{* * *}$ & & & & \\
\hline 30-nov-04 & $0.303^{* * *}$ & $0.831^{* * *}$ & $0.736^{* * *}$ & $0.767^{* * *}$ & $0.888^{* *}$ & $0.851^{* *}$ & $1^{* * *}$ & & & \\
\hline 7-dic-04 & $0.447 * * *$ & $0.775^{* * *}$ & $0.771^{* * *}$ & $0.779 * * *$ & $0.837^{* *}$ & $0.830^{* *}$ & $0.833^{* *}$ & $1 * * *$ & & \\
\hline 19-dic-04 & $0.218 * * *$ & $0.672 * * *$ & $0.669 * * *$ & $0.746^{* * *}$ & $0.651^{* *}$ & $0.671^{* *}$ & $0.760^{* *}$ & $0.776^{* *}$ & $1^{* * *}$ & \\
\hline 11-gen-05 & $0.361^{* * *}$ & $0.751^{* * *}$ & $0.655^{* * *}$ & $0.668^{* * *}$ & $0.808^{* *}$ & $0.874^{* *}$ & $0.771^{* *}$ & $0.809 * *$ & $0.696^{* *}$ & $1^{* * *}$ \\
\hline
\end{tabular}

$*, * *$ and ${ }^{* * *}$ values indicate correlations within dry stage, within wet stage and between dry and wet stages, respectively. 
$\left(\mathrm{R}^{2}=0.52\right)$. Even though the linear regression suffers from heteroschedasticity, it expresses the dominant role of soil texture. Once again we remind that south-facing slope is classified as VAG unit that is characterized by the typical clayey Cilento Flysch of this area (Nasta et al., 2017). We report a reduction in $\delta$ of approximately $50 \%$ when decreasing clay content by almost $100 \%$. Data belonging to north-facing hillslope align along the regression line which indicates larger dependence of soil moisture on sand content in the north-facing hillslope (classified as VAI and VAR soil-landscape units). All of the other remaining factors are generally minor except for the soil organic matter. Hu et al. (2009) observed that soil texture and soil organic matter were the main controlling factors on temporal variation of soil moisture. Yet, this indicator can be considered as a proxy for vegetation cover and it is interestingly negatively correlated to soil moisture patterns (Ruiz-Sinoga et al., 2011). The standard deviation of $\delta$ and ITS values are weakly correlated with environmental controlling factors that therefore do not influence temporal stability. Only exceptions are the weak roles of clay content and aspect on the $\sigma\left(\delta_{i}\right)$ as representative for soil and topography, respectively. The low spatial density of measurement locations and the direction of the six transects along the main slope gradients might favor the effect of non-local controls on soil moisture patterns as stated by Vanderlinden et al. (2012).

To examine whether or not the sampling strategy was based on a sufficient number of measurement data, we provide the ideal number of samples through prescribed percentage confidence errors ( $E=5 \%$ and $E=10 \%$ ) given in Eq. (3). Figure 5A shows the relationship between spatial-average soil moisture, $\bar{\theta}_{i}$ and its corresponding coefficient of variation, $C V_{\mathrm{j}}$ at time $j$ that is then used to calculate the minimum number of samples (MNS) required to guarantee an acceptable pre-fixed level of uncertainty. In accordance to previous studies, the relationship between $\bar{\theta}_{i}$ and $C V j$ is expressed through an exponential law instead of a linear regression line (Famiglietti et al., 2008; Brocca et al., 2010; Brocca et al., 2012; Korres et al., 2015). We observe that spatial variability of soil moisture is higher under dry conditions and nonlinearly decreases with increasing $\overline{\theta_{i}}$. Previous studies present similar regression coefficients reported in Figure 5A in areas with different environmental conditions (Famiglietti et al., 2008; Brocca et al., 2012). Nonlinear increase of MNS calculated by using Eq. (3) is related to sampling accuracy when spatial variability (in terms of $C V$ values) increases (Figure 5B). The conversion of $C V_{\mathrm{j}}$ into $\overline{\theta_{i}}$ is straightforward. The observed $C V_{j}$-values span from $21 \%$ to $59 \%$ and are associated to MNS of 2 to 11 by accepting $E=10 \%$ and of 7 to 52 by accepting $E=5 \%$.

Table 3. Pearson's correlation coefficients of $\overline{\delta_{i}}, \sigma\left(\delta_{i}\right)$, ITS with soil and topography controlling factors.

\begin{tabular}{lccc} 
& $\overline{\delta_{i}}$ & $\sigma\left(\delta_{i}\right)$ & IIS \\
Clay & $0.72^{*}$ & $0.48^{*}$ & 0.10 \\
SOM & $-0.21^{* *}$ & 0.06 & 0.08 \\
\hline$\rho_{b}$ & -0.08 & -0.12 & -0.11 \\
Aspect & -0.14 & $-0.28^{* *}$ & -0.07 \\
\hline Slope & $-0.55^{*}$ & -0.23 & 0.07 \\
Tang. curvature & 0.01 & 0.07 & -0.09 \\
\hline Plan. curvature & 0.11 & 0.05 & 0.06 \\
Ac & 0.04 & 0.08 & -0.03 \\
\hline
\end{tabular}

${ }^{*} \mathrm{P}<0.001 ;{ }^{*} \mathrm{P}<0.05$.

\section{Role of soil-landscape units in explaining space-time variation in soil moisture}

To provide some responses to the scientific questions posed in the Introdution section, we assume the soil-landscape units as hydrotopes (i.e. hydrologically similar units). We therefore partition the data set of soil moisture values in two sub-groups in order to test this hypothesis. We distinguish between those values belonging to the dominant unit (VAG) with 60 soil moisture locations and those ones belonging to the remaining units (VAI, VAR and CAG) with 22 soil moisture locations. Once again, we caution that the limited number of sampling locations was determined by several logistic constraints and impediments. The new sub-groups will be referred to as $V A G$ and MIX for the dominant and subordinate data sets, respectively.

The predictive ability of the easily-available environmental controls was tested through the PLSR analysis for both groups. Figure 6A shows the new spatial distributions of soil moisture values (VAG and MIX are represented by green and orange colors, respectively). A preliminary analysis of variance (ANOVA) test

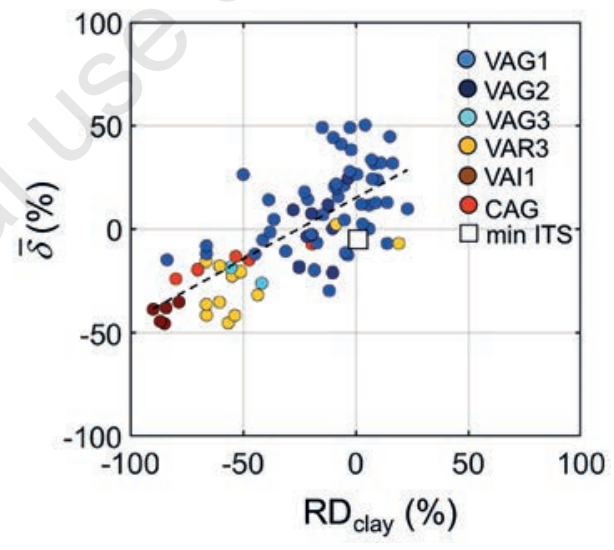

Figure 4. Relationship between relative difference in clay content $\left(\mathrm{RD}_{\text {clay }}\right)$ and relative difference in soil moisture. The markers in the scatter plot are colored according to soil-landscape units. The white square is the representative point of the study area (location 38).
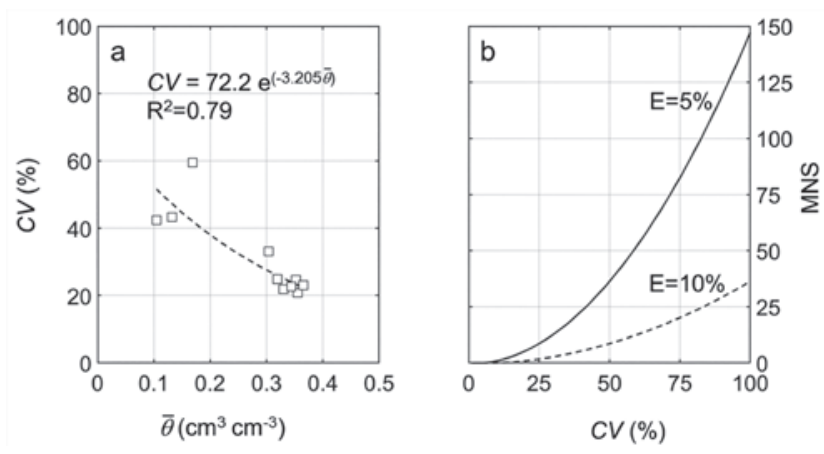

Figure 5. Relationship between: a) soil moisture areal mean and coefficient of variation (CV); and b) coefficient of variation (CV) and minimum number of samples (MNS) for prescribed $\mathrm{E}=5 \%$ (solid line) and $\mathrm{E}=10 \%$ (dashed line). 
established that the spatial-average soil moisture values of the two sub-groups are significantly different at $1 \%$ confidence level at each sampling date. The spatial variation of soil moisture patterns explained by the environmental controlling factors is illustrated in Figure 6B. We expect interwined influences of topography and soil properties on soil moisture patterns ( $\mathrm{Zhu}$ and Lin, 2011). It is worth noting that the soil moisture patterns belonging to the MIX group are well-explained (70\% in average) by soil and topography features (percentages consistently above $50 \%$ except for the $3^{\text {rd }}$ sampling date). On the one hand the explained variability reaches about $87 \%$ in two occasions under wet conditions. On the other hand the spatial organization of soil moisture patterns pertaining to the dominant soil-landscape unit is less effectively ( $45 \%$ in average) explained by soil and topography. Since the VAG unit is mostly covered by arable and pasture lands, additional disturbing factors influencing spatial variation of soil moisture patterns are mostly related to anthropogenic actions such as soil tillage practices that favor water infiltration during the growing season and surface lateral flow during the dormant season (Nasta et al., 2017). Hébrard et al. (2006) evidence the effect of landscape management induced by farmers who reshaped the landform with terraces and ditches in Mediterranean catchment located in southern France.

The predictive ability of the soil-topography controlling factors in the two sub-sets of data is showed in Figure 7. The comparison between observed and PLSR-modeled soil moisture is expressed through the $\mathrm{R}^{2}$ and RMSE. The environmental factors in the dominant unit (VAG) are fairly able to reproduce predicted soil moisture patterns $\left(\mathrm{R}^{2}=0.79\right)$. Yet data pairs cluster around the identity line (1:1 line) and model performance is not satisfactory ( $\mathrm{RMSE}=0.056 \mathrm{~cm}^{3} \mathrm{~cm}^{-3}$ ). In contrast, the simulated soil moisture patterns are very close to observed ones in the MIX group as corroborated by high $\mathrm{R}^{2}$ and low RMSE. Data pairs in Figure 6B align well around the identity line demonstrating low discrepancy between observed and predicted soil moisture patterns.

Table 4 lists the spatial-average values of environmental factors pertaining to the VAG and MIX groups. The main difference is evident in sand and clay contents and slope for soil and terrain characteristics, respectively. Group MIX has sand content and slope that double those belonging to VAG. Moreover the role of land use is important because MIX unit is covered by dense forest while VAG is dominated by arable and pasture lands.

Table 4. Spatial-average values of soil and topography controlling factors in the VAG and MIX sub-groups.

\begin{tabular}{lccc} 
& Units & VAG & MIX \\
I & - & 60 & 22 \\
Sand & $\%$ & 19.93 & 43.55 \\
\hline Silt & $\%$ & 35.81 & 34.62 \\
Clay & $\%$ & 44.26 & 21.83 \\
\hline SOM & $\%$ & 1.91 & 1.75 \\
$\rho_{b}$ & $\mathrm{~g} \mathrm{~cm}^{-3}$ & 1.28 & 1.33 \\
\hline Aspect & Degree & 216.54 & 254.66 \\
Slope & Degree & 10.21 & 17.19 \\
\hline Tang. curvature & $\mathrm{m}^{-1}$ & -0.05 & -0.08 \\
Plan. curvature & $\mathrm{m}^{-1}$ & 0.05 & -0.01 \\
\hline $\ln \left(\mathrm{A}_{c}\right)$ & $\mathrm{m}^{2}$ & 5.46 & 5.07 \\
\hline
\end{tabular}

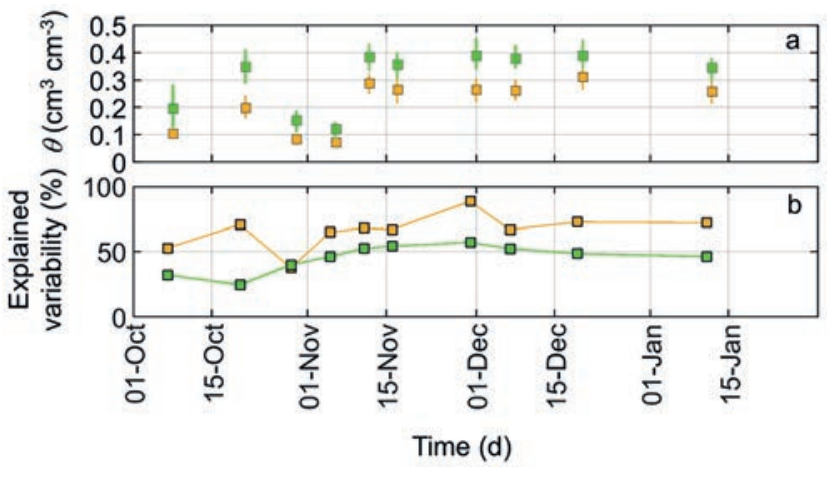

Figure 6. Daily values of a) spatial-average soil moisture values in VAG (green squares) and MIX (orange squares) sub-groups, vertical bars indicate \pm 1 standard deviation of soil moisture values; b) spatial variation of soil moisture patterns explained by soil and topography factors by using the PLSR technique. 


\section{Conclusions}

In this study we evaluated how soil textural characteristics and topographical features control temporal stability of soil moisture patterns in a sub-catchment of southern Italy, which can be viewed as representative of hilly zones of the Mediterranean Belt. The soil-landscape map was the available tool providing basic soil information on the study area. This classification proved to be a suitable tool to identify two different groups of soil moisture data with specific hydrologic behavior. The south-facing hillslope is classified as VAG unit because it is characterized by clayey soil and pasture and arable land. The north-facing hillslope has a steep profile, arenaceous soil and is covered by forest. The soil-landscape units can be considered as hydrotopes and represent a statistical tool that assist in deriving representative spatial-average soil moisture estimates.

The successful organization of ideal sampling schemes in longterm observatories largely depends on an in-depth understanding of spatio-temporal variability of soil moisture patterns retrieved during preliminary surveys like the one presented in this study. More specifically, we can design optimal soil moisture sensor distributions if we gain at least coarse information on temporal stability of soil moisture and its spatial covariation with environmental controlling factors. This prognostic analysis will serve for the installation of cosmic ray sensors and wireless sensor network in representative areas with different environmental features. The location of this instrumentation will be placed in light of the precious results given in this study.

\section{References}

Beaudette D.E., Dahlgren R.A., O'Geen A.T. 2013. Terrain-shape indeces for modeling soil moisture dynamics. Soil Sci Soc Am J. 77:1696-710.

Brocca L., Melone F., Moramarco T., Morbidelli R. 2009. Soil moisture temporal stability over experimental areas in central Italy. Geoderma. 148:364-74.

Brocca L., Melone F., Moramarco T., Morbidelli R. 2010. Spatialtemporal variability of soil moisture and its estimation across scales. Water Resourc. Res. 46 W02516.

Brocca L., Tullo T., Melone F., Moramarco T., Morbidelli R. 2012. Catchment scale soil moisture spatial-temporal variability. J. Hydrol. 422-423:63-75.

Chaney N.W., Roundy J.K., Herrera-Estrada J.E., Wood E.F. 2015. High-resolution modeling of the spatial heterogeneity of soil moisture: applications in network design. Water Resour. Res. 51:619-38.

Comegna V., Basile A. 1994. Temporal stability of spatial patterns of soil water storage in a cultivated Vesuvian soil. Geoderma 62:299-310.

Coppola A., Comegna A., Dragonetti G., Lamaddalena N., Kader A.M., Comegna V. 2011. Average moisture saturation effects on temporal stability of soil water spatial distribution at field scale. Soil \& Tillage Res. 114:155-64.

Famiglietti J.S., Ryu D.R., Berg A.A., Rodell M., Jackson T.J. 2008. Field observations of soil moisture variability across scales. Water Resour. Res. 44:W01423.

Friesen J., Rodgers C., Oguntunde P.G., Hendrickx J.M.H., van de Giesen N. 2008. Hydrotope-based protocol to determine average soil moisture over large areas for satellite calibration and validation with results from an observation campaign in the
Volta Basin, West Africa. IEEE Trans. Geosci. Remote Sens. 46:1995-2004.

Gómez-Plaza A., Alvarez-Rogel J., Albaladejo J., Castillo V.M. 2000. Spatial patterns and temporal stability of soil moisture across a range of scales in a semi-arid environment. Hydrol. Process. 14:1261-77.

Grayson R.B., Western A.W., Chiew F.H.S., Blöschl G. 1997. Preferred states in spatial soil moisture patterns: local and nonlocal controls. Water Resour. Res. 33:2897-908.

Hébrard O., Voltz M., Andrieux P., Moussa R. 2006. Spatio-temporal distribution of soil surface moisture in a heterogeneously farmed Mediterranean catchment. J. Hydrol. 329:110-21.

Huang X., Shi Z.H., Zhu H.D., Zhang H.Y., Ai L., Yin W. 2016. Soil moisture dynamics within soil profiles and associated environmental controls. Catena. 136:189-96.

Hu W., Shao M., Wang Q., Reichardt K. 2009. Time stability of soil water storage measured by neutron probe and the effects of calibration procedures in a small watershed. Catena. 79:72-82.

Hu W., Shao M., Han F., Reichardt K., Tan J. 2010. Watershed scale temporal stability of soil water content. Geoderma. 158:181-98.

Jacobs J.M., Mohanty B.P., Hsu E.-C., Miller D. 2004. SMEX02: Field scale variability, time stability and similarity of soil moisture. Remote Sens. Environ. 92:436-46.

Korres W., Reichenau T.G., Fiener P., Koyama C.N., Bogena H.R., Cornelissen T., Baatz R., Herbst M., Diekkrüger B., Vereecken H., Schneider K. 2015. Spatio-temporal soil moisture patterns - A meta-analysis using plot to catchment scale data. J. Hydrol. 520:326-41.

Lai X., Zhou Z., Zhu Q., Liao K. 2018. Comparing the spatio-temporal variations of soil water content and soil free water content at the hillslope scale. Catena. 160:366-75.

Liang W.L., Li S.-L., Hung F.-X. 2017. Analysis of the contributions of topographic, soil, and vegetation features on the spatial distributions of surface soil moisture in a steep natural forested headwater catchment. Hydrol. Process. 31: 3796-809.

Martínez-Fernández J., Ceballos A. 2003. Temporal stability of soil moisture in a large-field experiment in Spain. Soil Sci. Soc. Am. J. 67:1647-56.

Nasta P., Kamai T., Chirico G.B., Hopmans J.W. Romano N. 2009. Scaling soil water retention functions using particle-size distribution. J. Hydrol. 374:223-34.

Nasta P., Palladino M., Ursino N., Saracino A., Sommella A., Romano N. 2017. Assessing long-term impact of land use change on hydrologic ecosystem functions in a Mediterranean upland agro-forestry catchment. Sci. Total Environ. 605606:1070-82.

Page T., Beven K.J., Freer J., Neal C. 2007. Modelling the chloride signal at Plynlimon, Wales, using a modified dynamic TOPMODEL incorporating conservative chemical mixing (with uncertainty). Hydrol. Process. 21:292-307.

Park S.J., van de Giesen N. 2004. Soil-landscape delineation to define spatial sampling domains for hillslope hydrology. J. Hydrol. 295:28-46.

Robinson D.A., Campbell C.S., Hopmans J.W., Hornbuckle B.K., Jones S.B., Knight R., Ogden F., Selker J., Wendroth O. 2008. Soil moisture measurement for ecological and hydrological watershedscale observatories: a review. Vadose Zone J. 7:358-89.

Romano N. 2014. Soil moisture at local scale: measurements and simulations. J. Hydrol. 516:6-20.

Romano N., Nasta P., Bogena H., De Vita P., Stellato L., Vereecken H. 2018. Monitoring hydrological processes for land and water resources management in a Mediterranean 
ecosystem: The Alento River Catchment Observatory. Vadose Zone J. 17:180042.

Romano N., Chirico G.B. 2004. The role of terrain analysis in using and developing pedotransfer functions. In: Y.A. Pachepsky and W.J. Rawls (Eds.), Development of pedotransfer functions in soil hydrology. Elsevier Science B.V., pp. 273-294.

Ruiz-Sinoga J.D., Martínez-Murillo J.F., Gabarrón-Galeote M.A., García-Marín R. 2011. The e $\square$ ects of soil moisture variability on the vegetation pattern in Mediterranean abandoned fields (Southern Spain). Catena 85:1-11.

Santini A., Coppola A., Romano N., Terribile F. 1999. Interpretation of the spatial variability of soil hydraulic properties using a land system analysis. In: J. Feyen and K. Wiyo, (Eds.), Modelling of transport processes in soils at various scales in time and space, 24-26 Nov., Wageningen Pers, Wageningen, The Netherlands, pp. 491-500.

Schneider K., Huisman J.A., Breuer L., Zhao Y., Frede H.-G. 2008. Temporal stability of soil moisture in various semi-arid steppe ecosystems and its application in remote sensing. J. Hydrol. 359:16-29.

Susha Lekshmi S.U., Singh D.N., Tarantino A., Baghini, M.S. 2018. Evaluation of the performance of TDR and capacitance techniques for soil moisture measurement. Geotechn. Testing J. 41:292-306.

USDA. 1996. Keys to soil taxonomy. USDA, Washington, DC, USA. Vachaud G., Passerat de Silans A., Balabanis P., Vauclin M. 1985. Temporal stability of spatially measured soil water probability density function. Soil Sci. Soc. Am. J. 49:822-8.
Vanderlinden K., Vereecken H., Hardelauf H., Herbs M., Martınez G., Cosh M.H., Pachepsky Y.A. 2012. Temporal stability of soil water contents: a review of data and analyses. Vadose Zone J. 11:1-20.

Vereecken H., Huisman J.A., Bogena H., Vanderborght J., Vrugt J.A., Hopmans J.W. 2008. On the value of soil moisture measurements in vadose zone hydrology: a review. Water Resour. Res. 44:W00D06.

Vereecken H., Huisman J.A., Hendricks Franssen H.J., Brüggemann N., Bogena H.R., Kollet S., Javaux M., van der Kruk J., Vanderborght J. 2015. Soil hydrology: Recent methodological advances, challenges, and perspectives, Water Resour. Res. 51:2616-33.

Vincent S., Lemercier B., Berthier L., Walter C. 2018. Spatial disaggregation of complex Soil Map Units at the regional scale based on soil-landscape relationships. Geoderma. 311:130-42.

Zhu Q., Lin H. 2011. Influences of soil, terrain, and crop growth on soil moisture variation from transect to farm scales. Geoderma. 163:45-54.

Wang T., Wedin D.A., Franz T.E., Hiller J. 2015. Effect of vegetation on the temporal stability of soil moisture in grass-stabilized semi-arid sand dunes. J. Hydrol. 521:447-59.

Wang C., Zuo Q., Zhang R. 2008. Estimating the necessary sampling size of surface soil moisture at different scales using a random combination method. J. Hydrol. 352:309-21.

Wei L., Dong J., Gao M., Chen X. 2017. Factors controlling temporal stability of surface soil moisture: A watershed-scale modeling study. Vadose Zone J. 16 [Epub ahead of print]. 